Supplement of The Cryosphere, 13, 1709-1727, 2019

https://doi.org/10.5194/tc-13-1709-2019-supplement

(C) Author(s) 2019. This work is distributed under

the Creative Commons Attribution 4.0 License.

(c) (1)

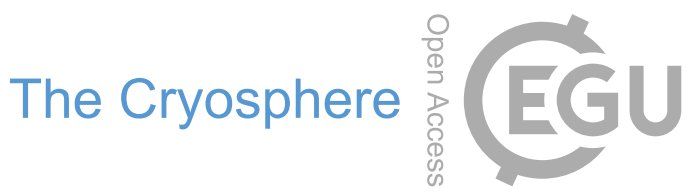

Supplement of

\title{
Multi-year evaluation of airborne geodetic surveys to estimate seasonal mass balance, Columbia and Rocky Mountains, Canada
}

Ben M. Pelto et al.

Correspondence to: Ben M. Pelto (pelto@unbc.ca)

The copyright of individual parts of the supplement might differ from the CC BY 4.0 License. 


\section{Supplemental Information}

\section{Introduction}

Here we provide additional details that relate to the data used in our study and associated methods.

\section{S1. Snow Density}

5 Given average winter snow depth $>4 \mathrm{~m}$ on our study glaciers, we had numerous $6 \mathrm{~m}$ pits, and the time savings in conducting snow cores in lieu of snow pits allowed us to obtain more density measurements, more effectively reducing density uncertainty. The corer also allowed us to sample internal ice lenses, which are difficult to measure with a snow sampler. We used a snow saw (G3 bone saw) to collect discrete samples (3-25 cm length) from the snow cores (Gabrielli et al., 2010; McGrath et al., 2018), avoiding areas where the core broke, to ensure a known volume, with the goal of sampling nearly all intact material

10 from the core (Figure S7). We noticed that core cuttings would accumulate at the bottom of the hole with each section of core taken, and so used care to avoid sampling these cuttings, which typically occupied the top 5-20 cm of the core but increased in amount with depth. We took spring snow density measurements at three locations at each site, (low, middle and high). Often, the density decreased with each subsequent core up-glacier, and thus we applied a linear regression of density and elevation to our depth measurements when converting to water equivalent. When there was no linear gradient, we averaged the snow

15 density measurements to produce a glacier-wide snow density. We also found that if our lowest snow core was very low (e.g. on the toe of the glacier), these wind-swept locales often had the lowest density snow. In this case, we assigned the density of the lowest site to measurements of snow from the elevation range of the toe, and then used the upper two sites to determine density everywhere else, as to not bias the gradient or glacier-wide average with a sample unrepresentative of the glacier atlarge.

\section{S2. Uncertainty Assessment}

We analyzed snow and ice-free terrain to derive statistical indicators of bias and data dispersion from $\triangle \mathrm{DEM}$ over stable terrain using a late summer DEM as a reference, and report the mean, median and normalized median absolute deviation (NMAD) over stable terrain (Table 3). We bias correct the height change over the glacier surfaces using the systematic elevation difference over stable terrain $\left(h_{d D E M}\right)$ in the $\triangle$ DEMs. This bias correction ranged from -0.09 to $0.05 \mathrm{~m}$ and averaged -0.01 $25 \mathrm{~m}$. NMAD reveals random errors that are typically below $\pm 0.3 \mathrm{~m}$, with a maximum of $0.6 \mathrm{~m}$ (Table 3 ). This maximum error occurred for Zillmer Glacier in late summer 2017 when the separation between site visit and ALS survey was large and new snow covered the glacier during the ALS survey (Table 2).

Random uncertainty stems from three sources that we assume to be independent: i) elevation change uncertainty $\left(\sigma h_{\triangle D E M}\right)$, ii) glacier zone delineation uncertainty $(\sigma A)$, and iii) volume to mass density conversion uncertainty $(\sigma \rho)$. Elevation change uncertainty is derived from the $\sigma$ of height change over stable terrain $(\sigma h)$ after correction for effective sample size $\left(N_{\text {eff }}\right)$ : 
$\sigma h_{\triangle D E M}=\frac{2 \sigma h}{\sqrt{N_{e f f}}}$

where the effective sample size is defined as (Bretherton et al., 1999):

$N_{\text {eff }}=\frac{n \cdot d x}{2 \cdot L}$

where $n$ is the number of pixels of stable terrain, $d x$ is the spatial resolution $(1 \mathrm{~m})$, and $L$ is the decorrelation length. Stable

terrain generally covered $10-20 \mathrm{~km}^{2}$. We determined $L$ by plotting semivariance (Figure S3) for randomly selected coordinate pairs $(n=10,000)$ against distance for ten separate simulations and defined $L$ as the distance at which semivariance becomes asymptotic ( $5 \%$ change threshold). Decorrelation length averaged $0.75 \mathrm{~km}$ and varied from 0.5 to $1.3 \mathrm{~km}$. For delineation of ice/firn/snow zones from satellite imagery (Figure S1), we applied a buffering method (Granshaw and Fountain, 2006) to the perimeter of each zone that was not at the glacier boundary. Our satellite imagery resolution varied from 3 to $15 \mathrm{~m}$, so we chose a buffer of four times the largest pixel size, to derive an uncertainty in area per zone:

$$
\sigma A=\text { perimeter } \cdot 4 \cdot d x
$$

This $60 \mathrm{~m}$ buffer accounts for uncertainty in zone delineation and changes in the positions of the zone boundaries occurring between ALS and satellite imagery acquisition dates. Due to the high resolution of our DEMs, planimetric uncertainties were all $<1 \%$ of glacier area (average 0.6\%), using a four-pixel buffer per Abermann et al. (2010), and they were omitted from uncertainty analysis (Belart et al., 2017). Total random uncertainty in volume change is:

$$
\sigma \Delta V=\sqrt{\left(\sigma h_{\Delta D E M}(p+5(1-p)) A\right)^{2}+\left(\sigma A \cdot h_{\Delta D E M}\right)^{2}}
$$

where $\mathrm{A}$ is the area of a given glacier and $\mathrm{p}$ is the percentage of surveyed area, which averaged 99.1\% (Table 2). We assume a factor of five for the elevation change uncertainty of non-surveyed areas (Berthier et al., 2014). Random uncertainty on geodetic mass balance is:

$50 \quad \sigma \Delta M=\sum_{i} \sqrt{\left(\sigma \Delta V_{i} \cdot \rho_{i}\right)^{2}+\left(\sigma \rho_{i} \cdot \Delta V\right)^{2}} \cdot \frac{A_{i}}{A_{t o t}}$

where $\rho_{i}$ is individual density conversion values with associated uncertainties $\left( \pm \sigma \rho_{i}\right)$ for spring snow, late summer snow, firn, and ice (Table 4). Prior to being summed to produce a final uncertainty, each zone (ice/firn/snow) is considered separately for $\mathrm{B}_{\mathrm{a}}$, with $\Delta \mathrm{V}_{\mathrm{i}}$ and $\mathrm{A}_{\mathrm{i}}$ the volume and area change of each zone respectively.

Firn compaction or fresh snow on the surveyed surface introduce systematic uncertainty on geodetic balance. On Drangajökull

55 ice cap, where $B_{w}$ is more than $1 \mathrm{~m}$ w.e. greater than our average $B_{w}$, firn compaction and fresh snow densification increased geodetic $\mathrm{B}_{\mathrm{w}}$ by $8 \%$. Fresh snow off-glacier was negligible in all but a few cases. We thus assume a systematic uncertainty $\left(\sigma \Delta M_{s y s}\right)$ of $10 \%$ on $\mathrm{B}_{\mathrm{a}, \mathrm{w}}$. Collectively, random and systematic uncertainty thus yield total uncertainty in mass balance:

$$
\sigma B_{\text {geod }}=\sqrt{(\sigma \Delta M)^{2}+\left(\sigma \Delta M_{s y s}\right)^{2}}
$$

To determine uncertainty in glaciological mass balance, we derive a mean density $(\rho)$ of mass change: 
$60 \rho=\frac{\rho_{\text {ice }} \cdot A_{\text {ice }}+\rho_{\text {firn }} \cdot A_{\text {firn }}+\rho_{\text {snow }} \cdot A_{\text {snow }}}{A_{\text {tot }}}$

and uncertainty in height change:

$\sigma \Delta h_{\text {glac }}=\sqrt{\sigma \Delta h_{\text {surv }}^{2}+\sigma h_{o b s}^{2}}$

where $\sigma \Delta h_{\text {surv }}$ is the uncertainty in survey height correction applied to the glaciological balance, estimated as a $50 \%$ uncertainty in height correction (m). Survey uncertainty is assigned to glaciological balance (Table 3) instead of geodetic

65 balance due to the near-synchronous timing of our ALS surveys and the staggered timing inherent in our glaciological data collection (Table 2). Locations where four measurements were taken indicated a $\sigma$ of $4 \%$ for spring and $8 \%$ for summer, but we conservatively use $10 \%$ as the uncertainty in height change measurements to incorporate potential uncertainty introduced by small-scale variability of snow depth, probing of the incorrect surface, and possible self-drilling or plucking of ablation stakes $\left(\sigma h_{o b s}\right.$ of $\pm 0.20 \mathrm{~m}$ for $\mathrm{B}_{\mathrm{a}}$ and $\pm 0.40 \mathrm{~m}$ for $\left.\mathrm{B}_{\mathrm{w}}\right)$. Uncertainty in glaciological mass balance is calculated as:

$70 \sigma B_{a, w}=\sqrt{\sigma \Delta h_{g l a c}^{2} \cdot \rho^{2}+\sigma \rho^{2} \cdot B_{a, w}^{2}}$

where $\sigma \rho$ is the uncertainty on density taken to be $10 \%$ of $\rho$, to account for uncertainty in density measurements and extrapolation of those measurements. The uncertainty in extrapolation of glaciological observations to glacier-wide mass balance $\left(\sigma_{E x t}\right)$ is taken as the $\sigma$ of the different calculations of mass balance for each season. Glaciological mass balance uncertainty is thus:

$75 \quad \sigma B_{g l a c}=\sqrt{\sigma B_{a, w}^{2}+\sigma_{E x t}^{2}}$

For both geodetic and glaciological mass balance, $\mathrm{B}_{\mathrm{s}}$ was derived as the difference of annual and summer balance (Eqn. 1), and thus uncertainty on $\mathrm{B}_{\mathrm{s}}$ yields:

$\sigma B_{s}=\sqrt{\sigma B_{a}^{2}+\sigma B_{w}^{2}}$

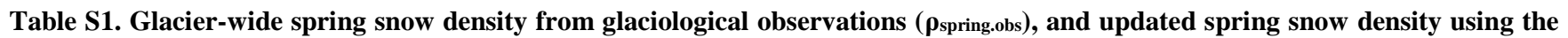
80 linear relation ( $\rho$ spring.lin) of Julian day versus snow density (Figure 3). No observed density implies no winter balance trip occurred,

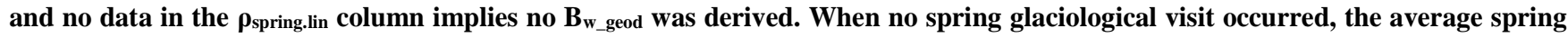
snow density for the sites' available record was used.

\begin{tabular}{llll}
\hline Year & Glacier & $\begin{array}{l}\rho_{\text {spring.obs }} \\
\left(\mathrm{kg} \mathrm{m}^{-3}\right)\end{array}$ & $\begin{array}{l}\rho_{\text {spring.lin }} \\
\left(\mathrm{kg} \mathrm{m}^{-3}\right)\end{array}$ \\
\hline 2018 & Zillmer & 517 & 457 \\
2018 & Nordic & 426 & 411 \\
2018 & Illecillewaet & - & 461 \\
2018 & Haig & - & 420 \\
2018 & Conrad & 407 & 413 \\
2018 & Kokanee & 395 & 419 \\
2017 & Zillmer & 381 & 492 \\
2017 & Nordic & 403 & 463
\end{tabular}




\begin{tabular}{llll}
2017 & Illecillewaet & 443 & 449 \\
2017 & Haig & 420 & 420 \\
2017 & Conrad & 500 & 518 \\
2017 & Kokanee & 415 & 517 \\
2016 & Zillmer & 447 & 459 \\
2016 & Nordic & 541 & 496 \\
2016 & Illecillewaet & 456 & 456 \\
2016 & Haig & 420 & 420 \\
2016 & Conrad & 480 & 453 \\
2016 & Kokanee & 459 & 459 \\
2015 & Zillmer & 554 & - \\
2015 & Nordic & 452 & 416 \\
2015 & Illecillewaet & - & - \\
2015 & Haig & 420 & - \\
2015 & Conrad & 481 & 472 \\
2015 & Kokanee & 466 & - \\
\hline
\end{tabular}

85 Table S2. Shallow firn core densities. Presumed year is the year the firn was deposited. Kokanee 2016 sample presumed age 2013 was directly overlain by 2016 snow (Figure S8); mass balance observations in 2015 indicated no retained snow in 2015 , and a loss of 2014 snow at the core location.

\begin{tabular}{llllllll}
\hline Glacier & $\begin{array}{l}\text { Obs. } \\
\text { Year }\end{array}$ & Presumed Year & Depth $(\mathrm{cm})$ & Firn length $(\mathrm{cm})$ & $\begin{array}{l}\text { Elev. } \\
(\mathrm{m})\end{array}$ & $\begin{array}{l}\text { Density } \\
\left(\mathrm{kg} \mathrm{m}^{-3}\right)\end{array}$ & $\begin{array}{l}\text { Years } \\
\text { back }\end{array}$ \\
\hline Nordic & 2017 & 2016 & $610-960$ & 350 & 2745 & 584 & 1 \\
Nordic & 2017 & 2015 & $960-1020$ & 60 & 2745 & 669 & 2 \\
Nordic & 2017 & 2014 & $1020-1100$ & 80 & 2745 & 664 & 3 \\
Zillmer & 2015 & 2014 & $455-585$ & 130 & 2527 & 623 & 1 \\
Zillmer & 2017 & 2016 & $510-555$ & 55 & 2527 & 553 & 1 \\
Kokanee & 2016 & 2013 & $420-440$ & 20 & 2660 & 776 & 3 \\
Kokanee & 2017 & 2016 & $540-605$ & 65 & 2660 & 650 & 1 \\
Illecillewaet & 2017 & 2016 & $500-335$ & 165 & 2606 & 685 & 1 \\
\hline
\end{tabular}

90 Table S3. Height change uncertainty as defined in supplemental equations 1 and 2.

\begin{tabular}{cccc}
\hline Year & Glacier & $\begin{array}{c}\sigma \mathrm{h}_{\triangle \mathrm{DEM}} \\
\mathrm{B}_{\mathrm{a}}(\mathrm{m})\end{array}$ & $\begin{array}{c}\sigma \mathrm{h}_{\triangle \mathrm{DEM}} \\
\mathrm{B}_{\mathrm{w}}(\mathrm{m})\end{array}$ \\
\hline 2018 & Zillmer & - & 0.04 \\
2018 & Nordic & - & 0.05 \\
2018 & Illecillewaet & - & 0.07 \\
2018 & Haig & - & 0.09 \\
2018 & Conrad & - & 0.05
\end{tabular}




\begin{tabular}{cccc}
2018 & Kokanee & - & 0.07 \\
2017 & Zillmer & 0.03 & 0.05 \\
2017 & Nordic & 0.02 & 0.02 \\
2017 & Illecillewaet & 0.03 & 0.07 \\
2017 & Haig & 0.05 & 0.07 \\
2017 & Conrad & 0.02 & 0.05 \\
2017 & Kokanee & 0.02 & 0.07 \\
2016 & Zillmer & 0.02 & 0.06 \\
2016 & Nordic & 0.03 & 0.06 \\
2016 & Illecillewaet & 0.05 & 0.08 \\
2016 & Haig & 0.04 & 0.07 \\
2016 & Conrad & 0.02 & 0.06 \\
2016 & Kokanee & 0.02 & 0.07 \\
2015 & Zillmer & - & - \\
2015 & Nordic & 0.03 & 0.02 \\
2015 & Illecillewaet & - & - \\
2015 & Haig & - & - \\
2015 & Conrad & 0.02 & 0.04 \\
2015 & Kokanee & - & - \\
\hline All & Average & 0.03 & 0.06 \\
\hline
\end{tabular}




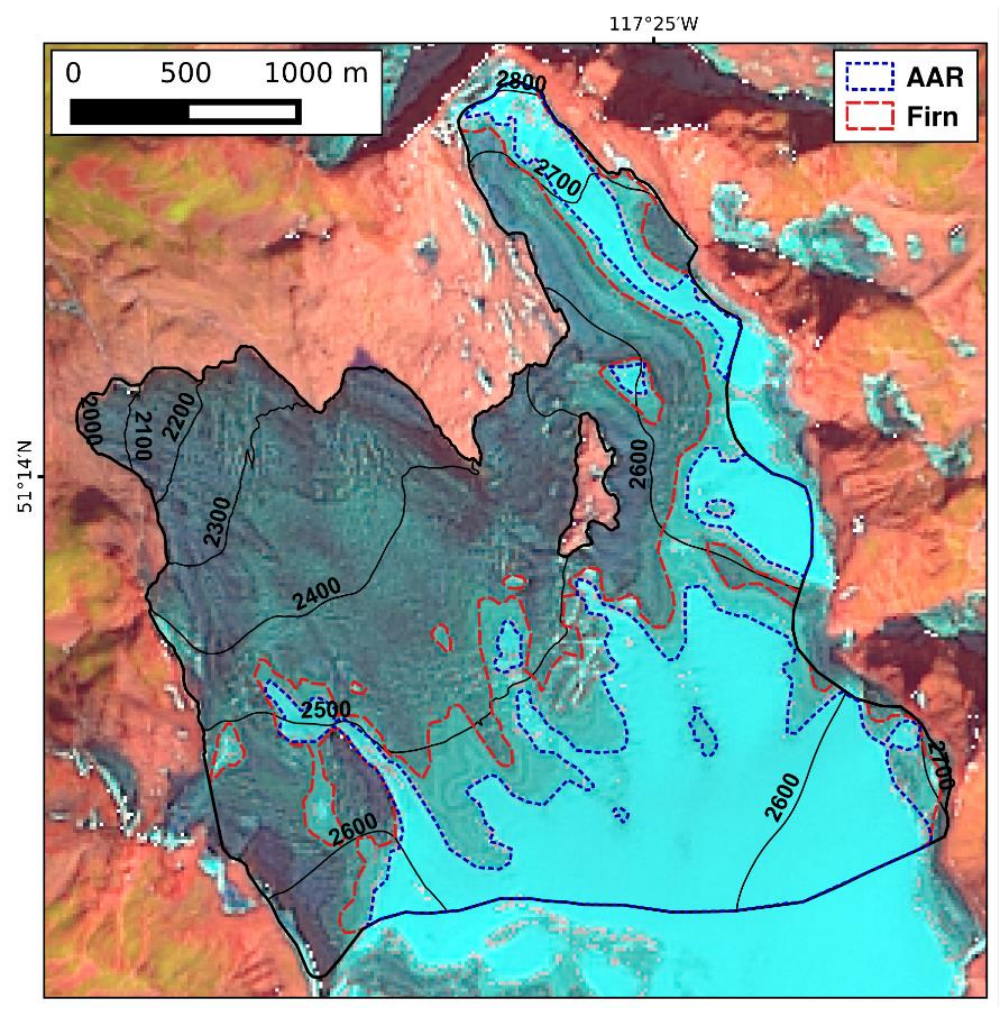

Figure S1: Surface classification of the Illecillewaet Glacier with a pan-sharpened Landsat 8 image from August 12, 2015. Firn area, and accumulation area are shown, with the remainder of the glacier (black outline), classified as ice.

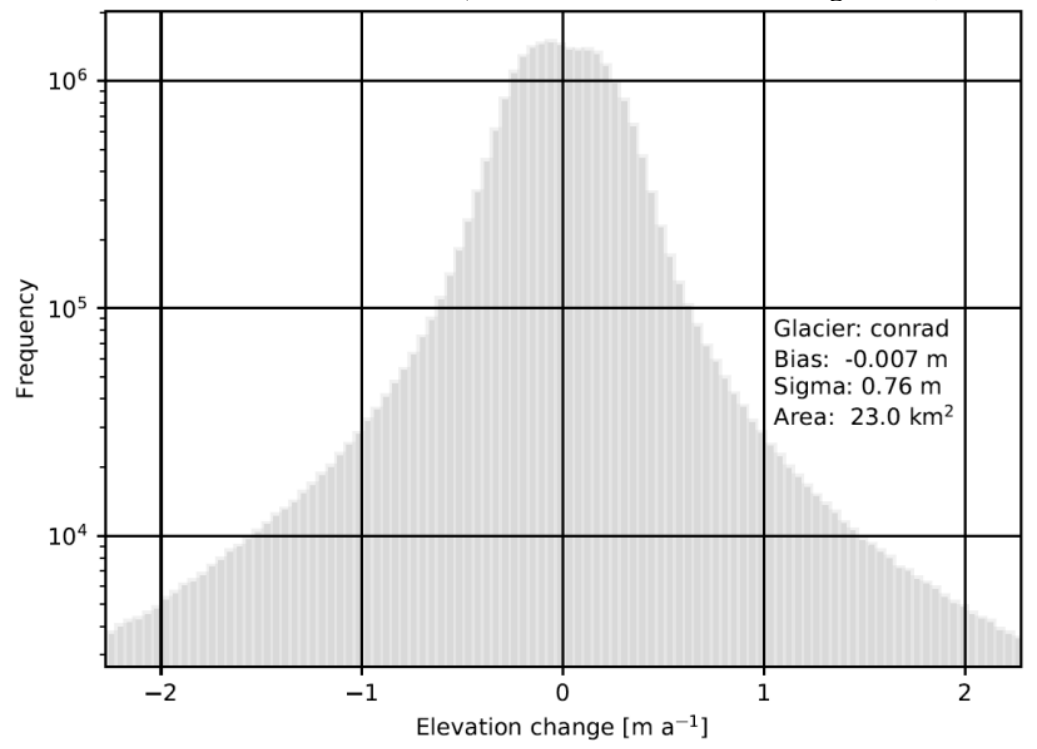

Figure S2: Example plot of off-ice observations for Conrad Glacier. Elevation change is plotted as off-ice observations between the late summer 2016 and late summer 2017 DEMs for Conrad Glacier. Height change was bias corrected by $\mathbf{- 0 . 0 0 7} \mathbf{m}$ based upon these observations. Off-ice area used in this plot covered $23 \mathrm{~km}^{2}$. 


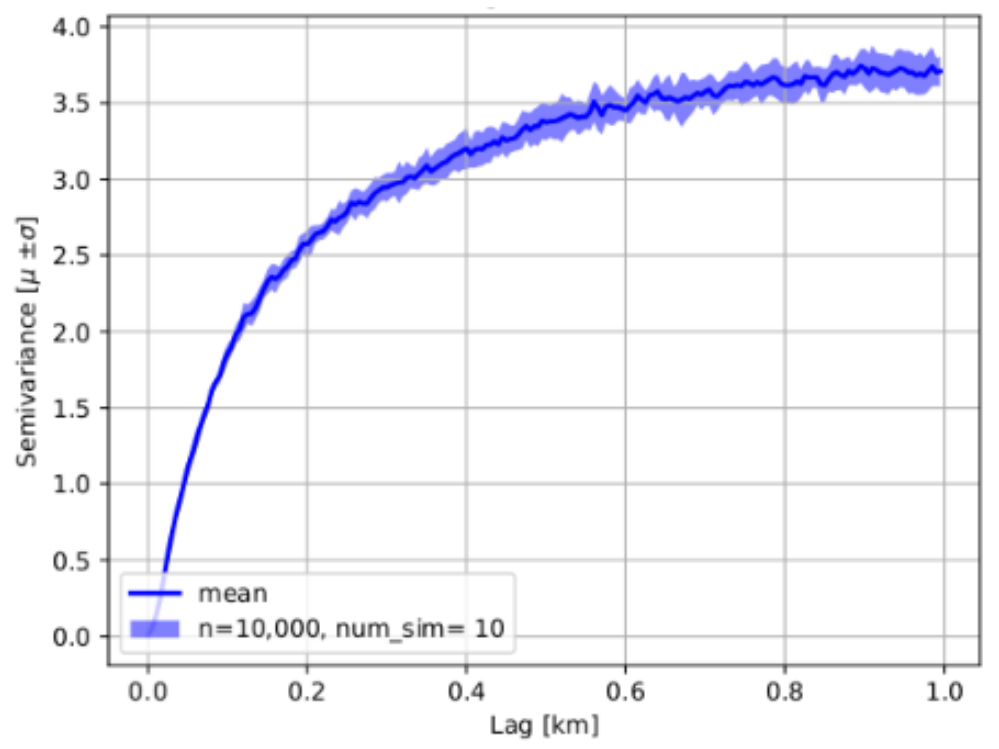

Figure S3: Example semivariogram for Conrad Glacier, winter 2018. The variogram was constructed using 10,000 random samples over 10 simulations. Decorrelation length was defined as the distance at which semivariance becomes asymptotic $(5 \%$ change threshold), $900 \mathrm{~m}$ in this example.

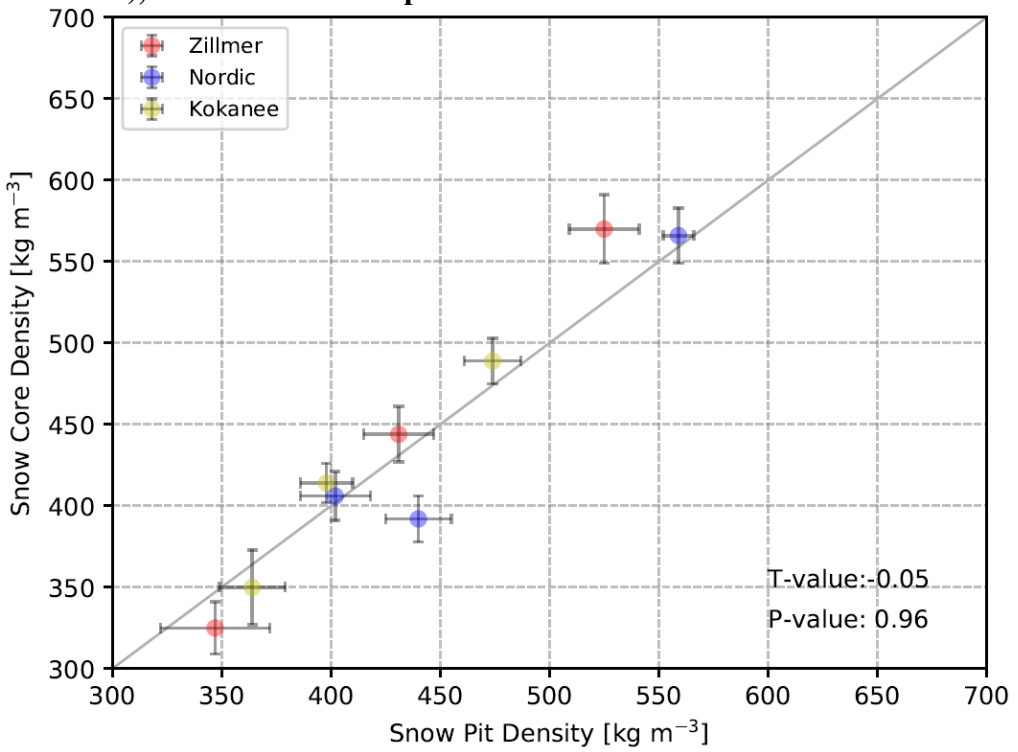

105 Figure S4: Comparison of snow pits and snow cores taken side-by-side. We conducted nine side-by-side pit/core comparisons which showed that our pit densities were a $0.2 \pm 5.7 \%$ heavier. The average absolute magnitude of disagreement between pit and core density was $4.8 \%$ ranging from $-11.5 \%$ to $+8 \%$. For snow pits we took a $100 \mathrm{~cm}^{-3}$ sample every 10 centimeters depth down the snow pit wall. For snow cores, we used a snow saw to take samples from each core, of up to $25 \mathrm{~cm}$-length. Taking discrete samples allowed for samples of known volume, avoiding broken sections of core, and avoided measuring the core fillings which fall to the bottom of the hole upon removal of the barrel after taking each core ( 1 m-length), then becoming the top of the subsequent core. 


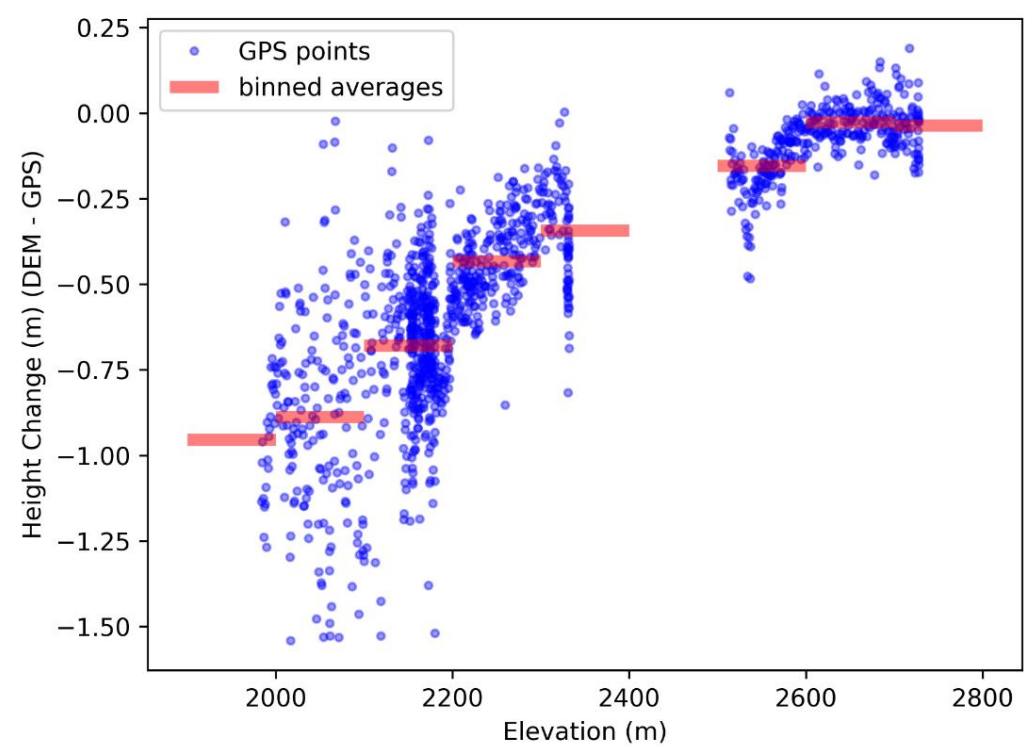

Figure S5: Zillmer Glacier kinematic GPS survey points subtracted from the subsequent ALS survey. The survey points were collected on August 12, 14 and 16, 2016 while the ALS survey was conducted on September 14, 2016. Height change points are averaged over $100 \mathrm{~m}$ elevation bands, and then assigned a density based upon surface classification from satellite observations to 115 convert height change to water equivalent. Glaciological data are then corrected with this data. Data between $2300-2500 \mathrm{~m}$ not shown as the base-station unit failed during this portion of surveying. Typically, time between GPS surveys and LiDAR acquisition was between 0-21 days. 

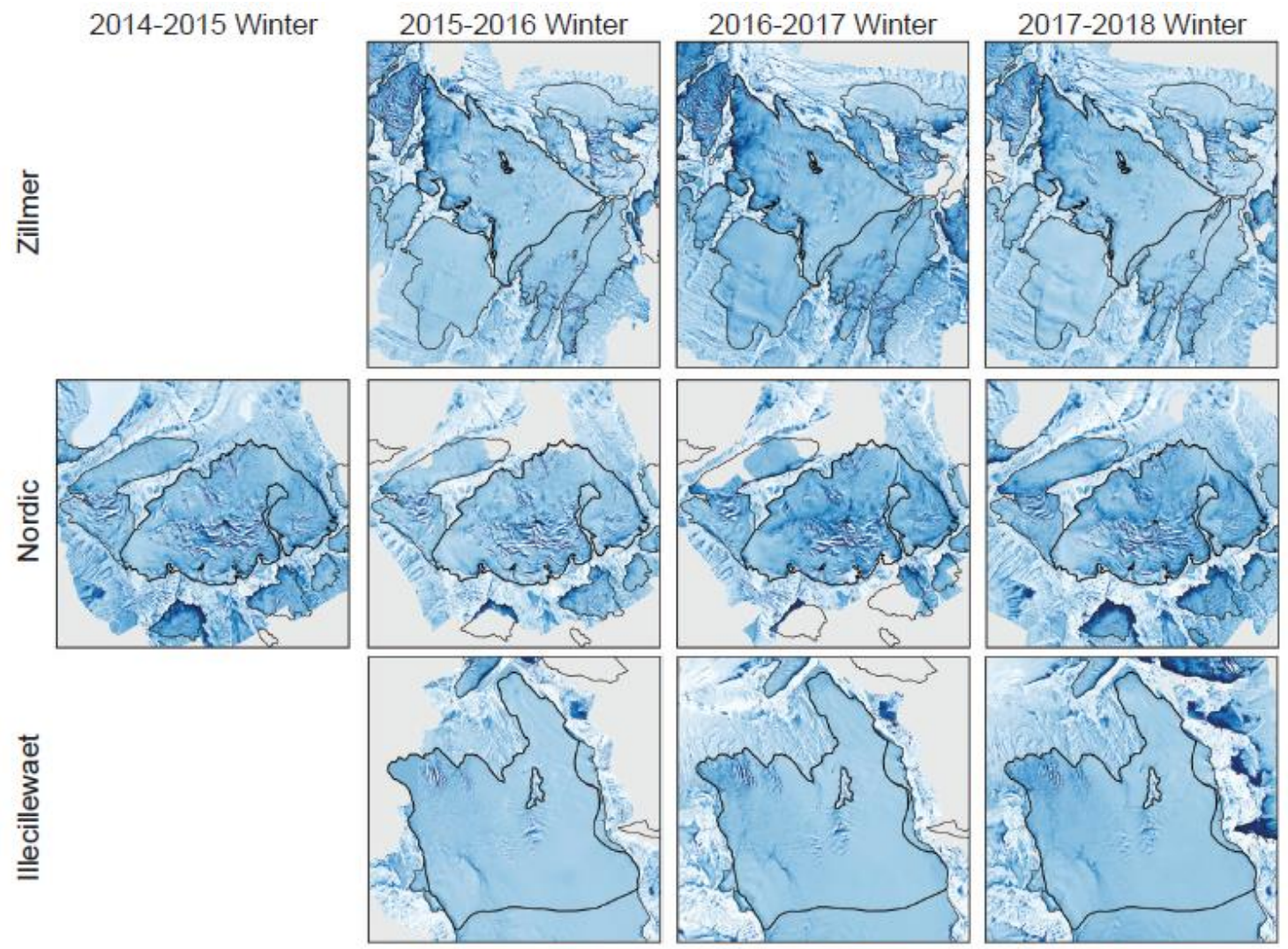

옾
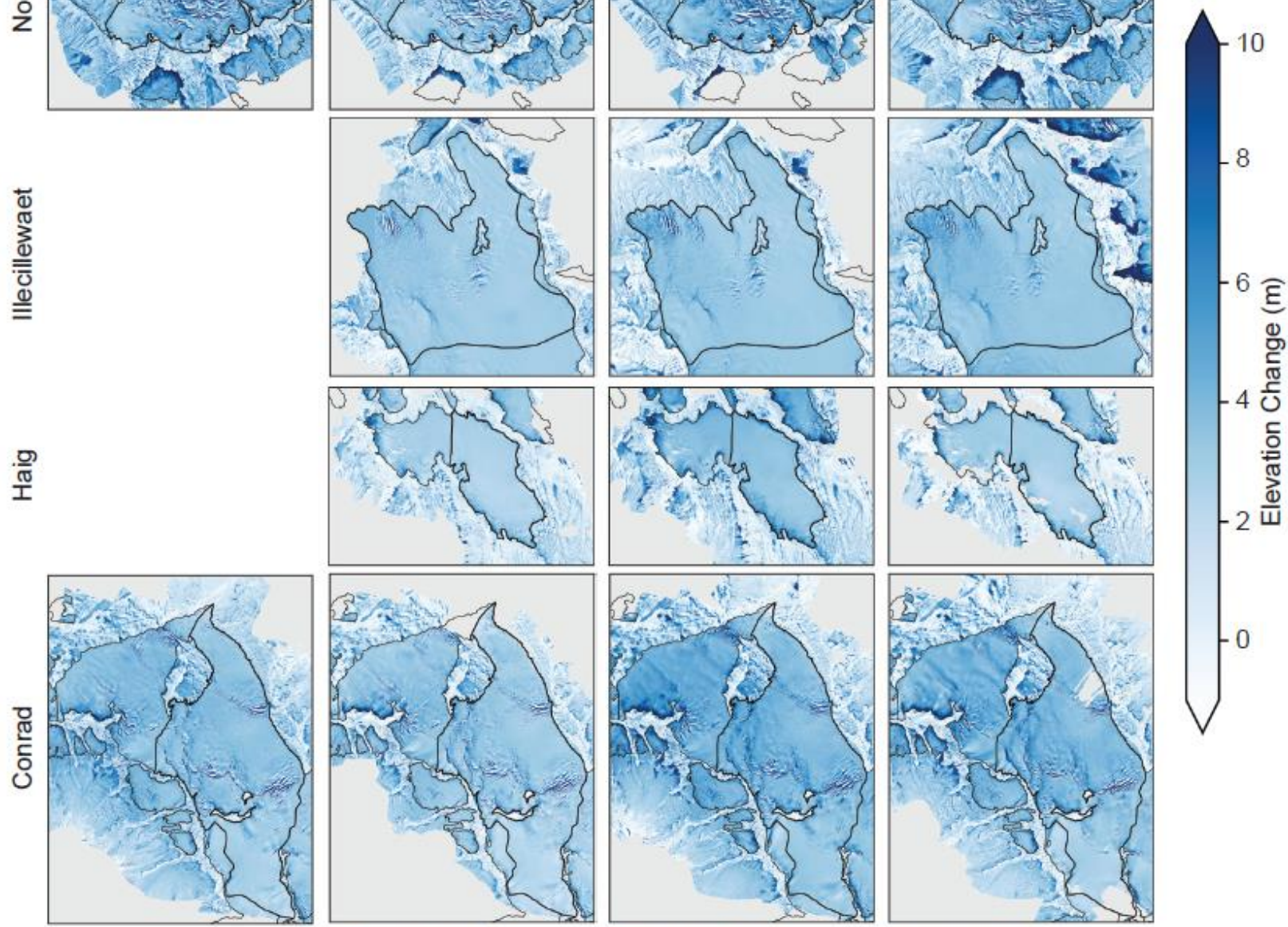

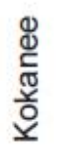
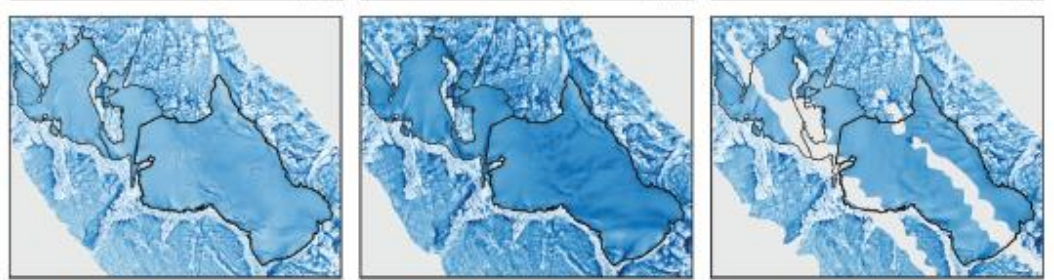
Figure S6: Winter surface height change for the Zillmer, Nordic, Illecillewaet, Haig, Conrad, and Kokanee glaciers for between 2014 and 2018. Study glaciers are outlined with thick black line and other glaciers with a thin black line.

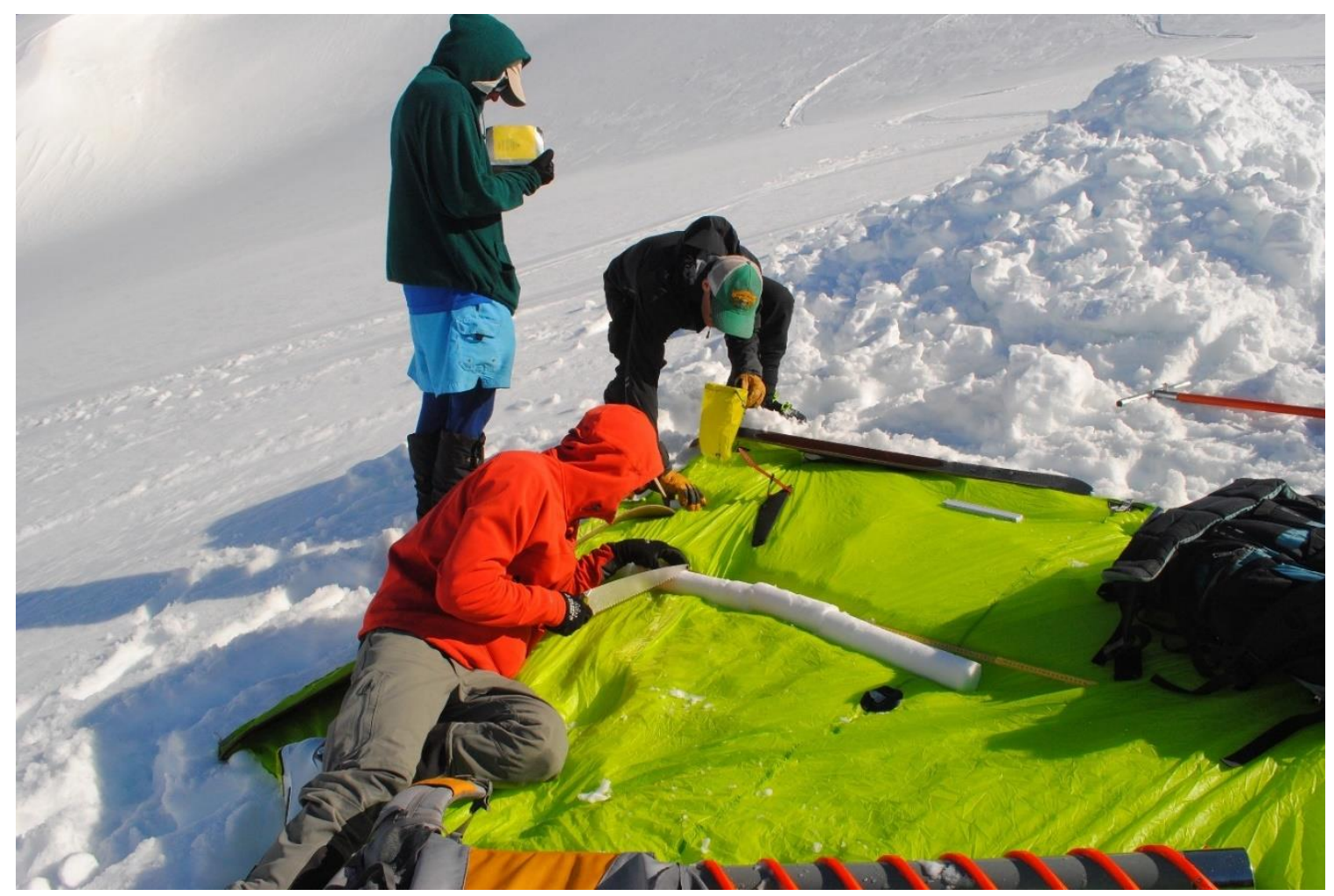

Figure S7. Sampling a snow core on the Kokanee glacier. Snow saw used to cut samples from the core. Photo by Jill Pelto. 


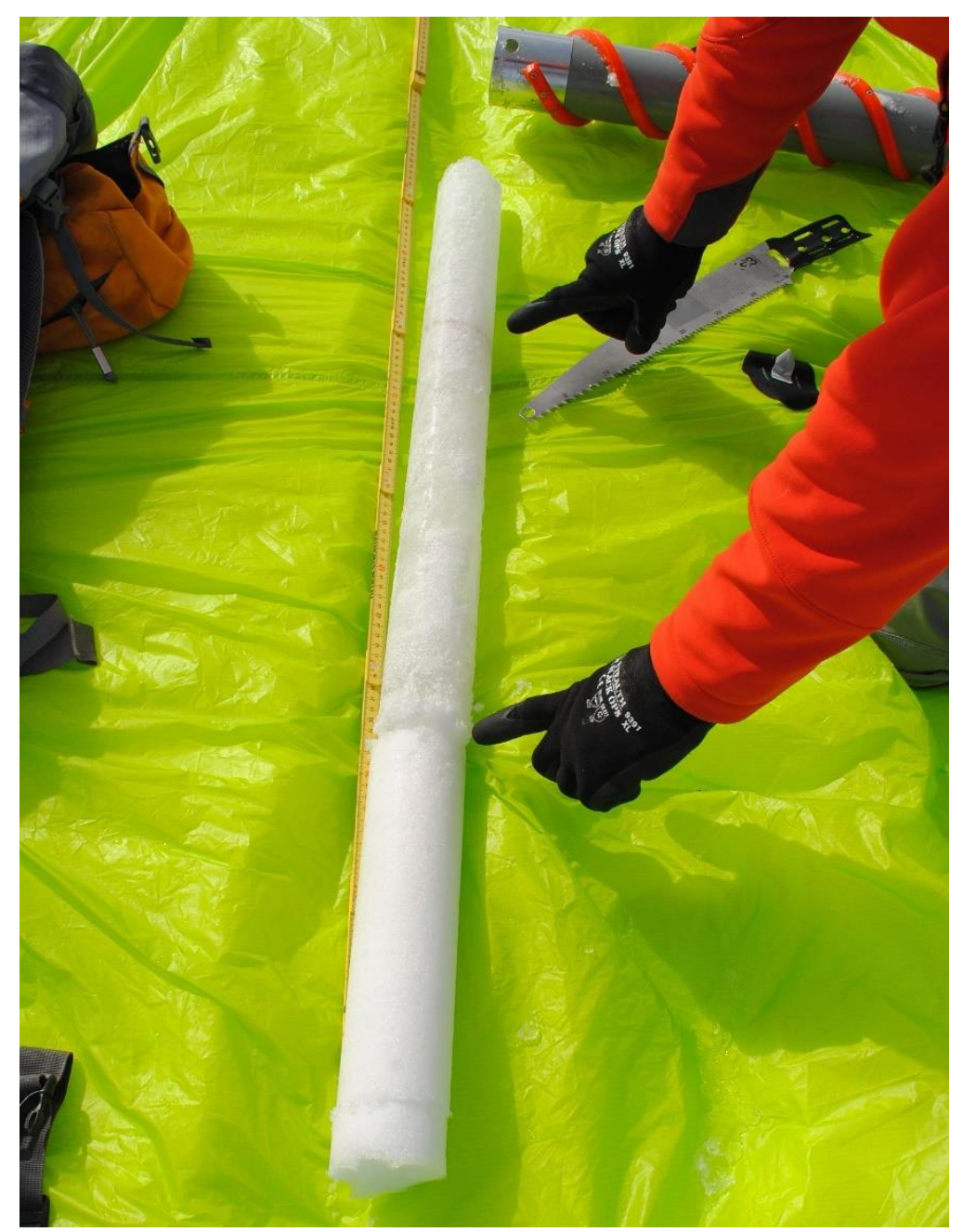

125 Figure S8. Snow and firn core from Kokanee Glacier, April 19, 2016. Core at photo bottom is snow, lower finger pointing to the snow-firn transition, and upper finger pointing to a dirty horizon marking an annual layer in the firn. Photo by Jill Pelto. 